\title{
Childhood OSA is an independent determinant of blood pressure in adulthood: Iongitudinal follow- up study
}

\author{
Kate Ching-ching Chan, ${ }^{1}$ Chun Ting Au, ${ }^{1}$ Lai Ling Hui, ${ }^{1}$ Yun Kwok Wing, ${ }^{2}$ \\ Albert Martin $\mathrm{Li}^{1}$
}

- Additional material is published online only. To view, please visit the journal online (http://dx.doi.org/10.1136/ thoraxjnl-2019-213692).

${ }^{1}$ Department of Paediatrics, The Chinese University of Hong Kong, Hong Kong SAR, China ${ }^{2}$ Sleep Assessment Unit, Department of Psychiatry, The Chinese University of Hong Kong, Hong Kong SAR, China

\section{Correspondence to} Professor Albert Martin Li, Department of Paediatrics, The Chinese University of Hong Kong, Hong Kong SAR, China; albertmli@cuhk.edu.hk

Received 11 June 2019 Revised 14 February 2020 Accepted 17 February 2020 Published Online First 24 March 2020

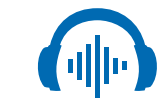

Listen to Podcast thorax.bmj.com

\section{SLinked}

- http://dx.doi.org/10.1136/ thoraxjnl-2020-214594

Check for updates

(c) Author(s) (or their employer(s)) 2020. No commercial re-use. See rights and permissions. Published by BMJ.

To cite: Chan KC, Au CT, Hui LL, et al. Thorax 2020;75:422-431

\section{ABSTRACT}

Background Current literature supports cross-sectional association between childhood obstructive sleep apnoea (OSA) and elevated blood pressure (BP). However, long-term cardiovascular outcomes in children with OSA remain unexplored.

Objective To evaluate the associations of childhood OSA with BP parameters in a prospective 10 year followup study.

Methods Participants were recruited from a cohort established for our previous OSA epidemiological study. They were invited to undergo clinical examination, overnight polysomnography and 24-hour ambulatory BP monitoring. Multivariate linear regression was used to assess the associations of baseline childhood OSA with BP outcomes at follow-up. Multivariable log-binomial regression was used with inverse probability weighting to assess the adjusted associations of childhood OSA with hypertension and non-dipping of nocturnal BP in adulthood.

Results 243 participants ( $59 \%$ male) attended the follow-up visit. The mean age was 9.8 ( $S D \pm 1.8$ ) and 20.2 (SD \pm 1.9 ) years at baseline and follow-up respectively, with a mean follow-up duration of 10.4 $(S D \pm 1.1)$ years. Childhood moderate-to-severe OSA was associated with higher nocturnal systolic blood pressure (SBP) (difference from normal controls: $6.5 \mathrm{~mm}$ $\mathrm{Hg}, 95 \% \mathrm{Cl} 2.9$ to 10.1$)$ and reduced nocturnal dipping of SBP $(-4.1 \%, 95 \% \mathrm{Cl}-6.3 \%$ to $1.8 \%)$ at follow-up, adjusted for age, sex, Body Mass Index and height at baseline, regardless of the presence of OSA at follow-up. Childhood moderate-to-severe OSA was also associated with higher risk of hypertension (relative risk (RR) 2.5, $95 \% \mathrm{Cl} 1.2$ to 5.3 ) and non-dipping of nocturnal SBP (RR $1.3,95 \% \mathrm{Cl} 1.0$ to 1.7 ) at follow-up.

Conclusion Childhood OSA was found to be an independent risk factor for adverse BP outcomes in adulthood.

\section{INTRODUCTION}

Obstructive sleep apnoea (OSA) is a common sleep disorder that affects all ages. The reported prevalence is $3 \%-5 \%$ in children and $9 \%-38 \%$ in adults. ${ }^{12}$ It is an important disease because of its association with cardiovascular, metabolic and neurobehavioural complications. ${ }^{3-7}$ Studies have consistently demonstrated elevated blood pressure (BP), a well-known risk factor for cardiovascular and cerebrovascular adverse outcomes, in children ${ }^{4689}$

\section{Key messages}

What is the key question?

- Does childhood obstructive sleep apnoea (OSA) have any long-term effects on blood pressure (BP) in adulthood?

What is the bottom line?

- Childhood OSA is an independent determinant of adult BP.

Why read on?

- This is the first longitudinal 10-year followup study to evaluate the effects of childhood OSA on long-term cardiovascular outcomes in adulthood.

and adults ${ }^{10}$ with OSA. Non-dipping of nocturnal BP (reduction of nocturnal BP $<10 \%$ from daytime level) has also been demonstrated in both adults and children with OSA. ${ }^{11-18}$ The phenomenon of nondipping in nocturnal BP precedes the development of hypertension in normotensive individuals. For patients with hypertension, non-dipping is associated with increased target organ damage and worse cardiovascular prognosis. ${ }^{11}$ Therefore, prevention of BP abnormalities and non-dipping is important to reduce the risk of developing cardiovascular adverse events. ${ }^{19}$ If OSA was proven to be one of the contributing factors, its treatment or prevention may help to reduce future cardiovascular morbidities and mortality.

Longitudinal studies in adults have shown an independent dose-response relationship between OSA and hypertension. ${ }^{20-22}$ This positive association, however, is not demonstrated across all studies. ${ }^{23}{ }^{24}$ Our previous study, one of a few paediatric longitudinal studies, found a significant association between childhood OSA and elevated BP at 4-year follow-up. ${ }^{4}$ The Penn State Child cohort reported an association between elevated systolic blood pressure (SBP) and vascular reactivity with new onset sleep-disordered breathing (SDB). ${ }^{25} 26$ Vlahandonis et al showed that improvement of SDB over a 4-year period is accompanied by a significant improvement in nocturnal $\mathrm{BP}^{27}$ On the other hand, a 5-year follow-up study did not find any relationship between the presence of SDB and BP. ${ }^{28}$ There are limitations in these published studies, namely, a 
relatively short follow-up period; only casual BP is measured in the majority of them; and the low SDB prevalence limits their study power. Whether childhood OSA is an independent determinant of adult BP outcomes remains undefined. Studies investigating the association between childhood OSA and nocturnal BP non-dipping have also yielded conflicting results. Some reported reduced nocturnal dipping in children with OSA or a reduction in dipping only in those with the most severe OSA, ${ }^{14-17}$ while others failed to find any relationship at all. ${ }^{829} 30$ To our knowledge, no longitudinal studies have examined whether childhood OSA affects the dipping pattern of nocturnal BP in adulthood.

In this prospective 10-year follow-up study, we explored the associations between childhood OSA and ambulatory blood pressure (ABP) outcomes in early adulthood. We hypothesised that childhood OSA was associated with higher BP and reduced nocturnal BP dipping at follow-up.

\section{METHODS}

\section{Participants}

This was a prospective longitudinal follow-up study of a cohort established between 2003 and 2005 for a childhood OSA epidemiological study. ${ }^{131}$ Children aged 6-13 years were randomly recruited from local primary schools. Details of recruitment can be found in our previous publications. ${ }^{131}$ At baseline, a total of 619 participants underwent overnight polysomnography (PSG), 250 were healthy controls, 103 had primary snoring (PS) while 266 had OSA (refer to the PSG and definitions section for definitions). For this follow-up study, all subjects from the original cohort were invited to undergo PSG and ABP monitoring. They were excluded from participation if they had cardiovascular, renal and neuromuscular diseases, chromosomal abnormalities or acute illness within 2 weeks of PSG. Written informed consent and assent were obtained from the parents and participants, respectively.

\section{Data collection and anthropometric measurements}

Parents completed a validated personal data and sleep symptom questionnaire at baseline, and the participants did so at follow-up. ${ }^{32}$ The weight and height of the subjects were measured on the day they underwent the PSG. Standing height without shoes was documented using a Harpenden stadiometer (Holtain, UK) to the nearest $0.1 \mathrm{~cm}$. Body weight (with the lightest clothing) measured to the nearest $0.1 \mathrm{~kg}$ was obtained by an electronic weighing scale (Tanita BF-522, Japan). Body Mass Index (BMI) was calculated as weight $/$ height ${ }^{2}\left(\mathrm{~kg} / \mathrm{m}^{2}\right)$ and converted to $z$-scores appropriate for age and sex according to local reference. ${ }^{33}$ Overweight and obesity were defined as BMI $z$-scores of $\geq 1.036$ and 1.645 , corresponding to the 85 th and 95 th percentiles, respectively. Pubertal stage at baseline visit was evaluated using a validated self-assessment questionnaire. ${ }^{34}$

\section{PSG and definitions}

Nocturnal PSG was carried out at the Prince of Wales Hospital. Baseline PSG was performed, manually edited and scored as described. ${ }^{1346}$ At follow-up, Siesta ProFusion III PSG monitor (Compumedics Telemed, Abbotsford, Victoria, Australia) was used to record the following parameters: electroencephalogram (F4/A1, C4/A1 and O2/A1), bilateral electro-oculogram, electromyogram of mentalis activity and bilateral anterior tibialis. Respiratory movements of the chest and abdomen were measured by inductance plethysmography. ECG and heart rate were continuously recorded from two anterior chest leads. Arterial oxyhaemoglobin saturation $\left(\mathrm{SaO}_{2}\right)$ was measured by a finger probe oximeter. Respiratory airflow pressure signal was obtained via a nasal catheter placed at the anterior nares and connected to a pressure transducer. An oronasal thermal sensor was used to detect absent airflow. Snoring was measured by a microphone placed near the throat. Body position was monitored via a body position sensor.

Respiratory events including obstructive apnoeas, mixed apnoeas, central apnoeas and hypopnoeas were scored based on the American Academy of Sleep Medicine (AASM) Manual for the Scoring of Sleep and Associated Events V.2.0. ${ }^{35}$ Respiratory effort-related arousals (RERAs) were scored when there was an arousal with a fall of $<50 \%$ from baseline in the amplitude of nasal pressure signal with flattening of the nasal pressure

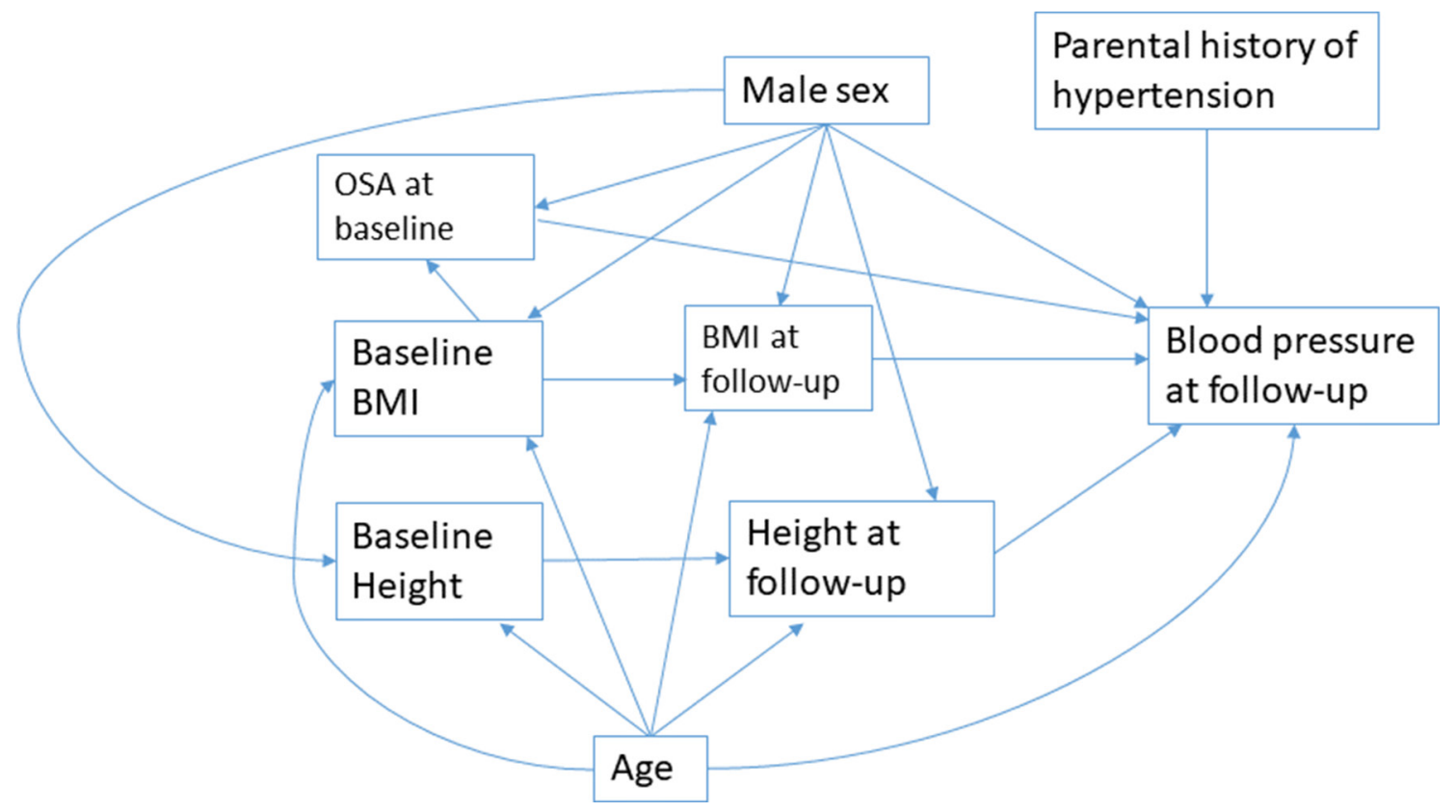

Figure 1 Potential relationships between exposures and blood pressure outcomes at follow-up. BMI, body mass index; OSA, obstructive sleep apnoea. 
Table 1 Characteristics of subjects with different baseline OSA severity

\begin{tabular}{|c|c|c|c|c|c|}
\hline & Normal & Primary snoring & Mild OSA & Moderate-to-severe OSA & \\
\hline Subject characteristics & $\mathrm{n}=98$ & $\mathrm{n}=49$ & $\mathrm{n}=75$ & $\mathrm{n}=21$ & P for trend* \\
\hline Male sex, n (\%) & $51(52.0)$ & $29(59.2)$ & $51(68.0)$ & $16(76.2)$ & 0.009 \\
\hline Prepubertal at baseline, $\mathrm{n}(\%)$ & $83(84.7)$ & 47 (95.9) & $65(86.7)$ & $19(90.5)$ & 0.53 \\
\hline \multicolumn{6}{|l|}{ Age (years) } \\
\hline Baseline & $9.9 \pm 1.8$ & $9.3 \pm 1.8$ & $9.9 \pm 1.8$ & $9.7 \pm 1.9$ & 0.94 \\
\hline Follow-up & $20.3 \pm 2.0$ & $20.0 \pm 1.9$ & $20.3 \pm 1.9$ & $19.5 \pm 2.1$ & 0.34 \\
\hline Follow-up length (years) & $10.4 \pm 1.0$ & $10.7 \pm 0.9$ & $10.3 \pm 1.1$ & $9.8 \pm 1.1$ & 0.10 \\
\hline \multicolumn{6}{|l|}{ Height (cm) } \\
\hline Baseline & $135.3 \pm 11.9$ & $132.2 \pm 11.6$ & $136.8 \pm 11.6$ & $135.8 \pm 13.0$ & 0.46 \\
\hline Follow-up & $166.5 \pm 8.4$ & $166.8 \pm 8.8$ & $168.8 \pm 9.4$ & $168.4 \pm 7.7$ & 0.088 \\
\hline \multicolumn{6}{|l|}{ BMI $\left(\mathrm{kg} / \mathrm{m}^{2}\right)$} \\
\hline Baseline & $17.4 \pm 3.1$ & $17.5 \pm 2.9$ & $18.5 \pm 3.2$ & $19.0 \pm 3.7$ & 0.008 \\
\hline Follow-up & $21.9 \pm 4.4$ & $21.8 \pm 3.2$ & $22.3 \pm 3.7$ & $22.0 \pm 4.4$ & 0.55 \\
\hline \multicolumn{6}{|l|}{ BMI z-score } \\
\hline Baseline & $0.30 \pm 1.03$ & $0.49 \pm 0.85$ & $0.65 \pm 1.00$ & $0.80 \pm 1.12$ & 0.007 \\
\hline Follow-up & $0.18 \pm 1.18$ & $0.29 \pm 0.85$ & $0.40 \pm 1.04$ & $0.31 \pm 1.01$ & 0.25 \\
\hline \multicolumn{6}{|l|}{ Overweight, n (\%) } \\
\hline Baseline & $26(26.5)$ & $14(28.6)$ & $27(36.0)$ & $10(47.6)$ & 0.044 \\
\hline Follow-up & $21(21.4)$ & $9(18.4)$ & $16(21.3)$ & $5(23.8)$ & 0.88 \\
\hline \multicolumn{6}{|l|}{ Habitual snoring, n (\%) } \\
\hline Baseline & $0(0.0)$ & $49(100.0) \dagger$ & $23(30.7) \dagger$ & $9(42.9) \dagger$ & $<0.001$ \\
\hline Follow-up & $12(12.2)$ & $17(34.7) \dagger$ & $20(26.7) \dagger$ & $4(19.0)$ & 0.073 \\
\hline \multicolumn{6}{|l|}{ OAHI (events/hour) } \\
\hline Baseline & $0.1(0-0.4)$ & $0.2(0-0.5)$ & $1.9(1.2-2.8) \dagger$ & $7.5(5.8-10.3) \dagger$ & $<0.001$ \\
\hline Follow-up & $0.7(0-3.7)$ & $1.5(0.5-5.5)$ & $1.7(0.4-4.7) \dagger$ & $5.3(1.4-8.7) \dagger$ & 0.002 \\
\hline \multicolumn{6}{|l|}{ ODI (events/hour) } \\
\hline Baseline & $0.1(0-0.3)$ & $0.2(0-0.5)$ & $0.5(0.2-1.1) \dagger$ & $3.2(1.4-5.2) \dagger$ & $<0.001$ \\
\hline Follow-up & $1.3(0.3-4.0)$ & $0.9(0.2-3.7)$ & $2.1(0.7-5.8)$ & $3.7(1.3-7.0) \dagger$ & 0.013 \\
\hline \multicolumn{6}{|l|}{ Arousal Index (events/hour) } \\
\hline Baseline & $5.7(4.6-7.7)$ & $6.1(4.7-7.7)$ & $7.1(5.3-8.5) \dagger$ & $10.3(8.0-13.1) \dagger$ & $<0.001$ \\
\hline Follow-up & $11.6(9.0-15.6)$ & $12.5(9.3-16.5)$ & $11.6(9.5-15.1)$ & $16.5(12.8-21.9) \dagger$ & 0.007 \\
\hline \multicolumn{6}{|c|}{ Parental history of hypertension, $\mathrm{n}(\%)$} \\
\hline Father & $21(21.4)$ & $15(30.6)$ & $21(28.0)$ & $7(33.3)$ & 0.20 \\
\hline Mother & $19(19.4)$ & $9(18.4)$ & $13(17.3)$ & $3(14.3)$ & 0.58 \\
\hline Either parent & $34(34.7)$ & $19(38.8)$ & $30(40.0)$ & $9(42.9)$ & 0.38 \\
\hline Both parents & $6(6.1 \%)$ & $5(10.2)$ & $4(5.3)$ & $1(4.8)$ & 0.75 \\
\hline
\end{tabular}

${ }^{*} \mathrm{P}$ values obtained from linear contrast tests and linear-by-linear association tests for continuous and categorical data, respectively. $t \mathrm{p}<0.05$ after Bonferroni adjustment, compared with the normal group.

BMI, Body Mass Index; OAHI, Obstructive Apnoea-Hypopnoea Index; ODI, Oxygen Desaturation Index; OSA, Obstructive Sleep Apnoea.

waveform, accompanied by snoring, noisy breathing or evidence of increased effort of breathing. A respiratory event was scored when it lasted $\geq 2$ breaths irrespective of its duration for children at baseline, and $10 \mathrm{~s}$ for adolescents and adults at follow-up based on the AASM recommendations. ${ }^{35}$ Arousal was defined as an abrupt shift in electroencephalogram frequency during sleep, which may include theta, alpha and/or frequencies greater than $16 \mathrm{~Hz}$ but not spindles, with $3-15 \mathrm{~s}$ in duration. In rapid eye movement sleep, arousals were scored only when accompanied by concurrent increase in submental electromyography amplitude. ${ }^{35}$
Obstructive Apnoea-Hypopnoea Index (OAHI) was defined as the total number of obstructive and mixed apnoeas and hypopnoeas per hour of sleep. Respiratory Disturbance Index was defined as the total number of obstructive and mixed apnoeas, hypopnoeas and RERAs per hour of sleep. Oxygen Desaturation Index (ODI) was defined as the total number of dips in arterial oxygen saturation $\geq 3 \%$ per hour of sleep. Arousal Index was the total number of arousals per hour of sleep. Respiratory Arousal Index was the total number of arousals per hour of sleep that were associated with apnoea, hypopnoea or flow limitation. 
Table 2 Baseline and follow-up BP of subjects by baseline OSA severity

\begin{tabular}{|c|c|c|c|c|c|}
\hline & Normal & Primary snoring & Mild OSA & Moderate-to-severe OSA & \\
\hline BP parameters & $\mathrm{n}=98$ & $\mathrm{n}=49$ & $\mathrm{n}=75$ & $\mathrm{n}=21$ & P for trend* \\
\hline \multicolumn{6}{|l|}{ Daytime SBP (mm Hg) } \\
\hline Baselinet & $112 \pm 10$ & $112 \pm 7$ & $113 \pm 8$ & $114 \pm 7$ & 0.35 \\
\hline$\geq 95$ th percentile, $\mathrm{n}(\%)$ & $0(0)$ & $0(0)$ & $1(1.7)$ & $0(0)$ & 0.38 \\
\hline Follow-up $\ddagger$ & $115 \pm 9$ & $116 \pm 10$ & $117 \pm 10$ & $118 \pm 8$ & 0.076 \\
\hline$\geq 135 \mathrm{~mm} \mathrm{Hg}, \mathrm{n}(\%)$ & $1(1.0)$ & $3(6.1)$ & $3(4.0)$ & $0(0.0)$ & 0.59 \\
\hline \multicolumn{6}{|l|}{ Daytime DBP (mm Hg) } \\
\hline Baselinet & $71 \pm 6$ & $73 \pm 6$ & $72 \pm 6$ & $73 \pm 4$ & 0.20 \\
\hline$\geq 95$ th percentile, $\mathrm{n}(\%)$ & $1(1.3 \%)$ & $2(6.1)$ & $2(3.4 \%)$ & $0(0.0)$ & 0.81 \\
\hline Follow-up $\ddagger$ & $72 \pm 6$ & $73 \pm 6$ & $73 \pm 6$ & $72 \pm 5$ & 0.68 \\
\hline$\geq 85 \mathrm{~mm} \mathrm{Hg}, \mathrm{n} \mathrm{( \% )}$ & $2(2.0)$ & $3(6.1)$ & $4(5.3)$ & $0(0.0)$ & 0.67 \\
\hline \multicolumn{6}{|l|}{ Night-time SBP (mm Hg) } \\
\hline Baselinet & $99 \pm 10$ & $98 \pm 6$ & $101 \pm 8$ & $106 \pm 11 \S$ & 0.011 \\
\hline$\geq 95$ th percentile, $\mathrm{n}(\%)$ & $10(13.2)$ & $0(0.0)$ & $6(10.3)$ & $5(29.4)$ & 0.36 \\
\hline Follow-up & $103 \pm 9$ & $104 \pm 9$ & $104 \pm 9$ & $111 \pm 10 \S$ & 0.007 \\
\hline$\geq 120 \mathrm{~mm} \mathrm{Hg}, \mathrm{n}(\%)$ & $3(3.1)$ & $1(2.0)$ & $4(5.4)$ & $6(28.6) \S$ & 0.001 \\
\hline \multicolumn{6}{|l|}{ Night-time DBP (mm Hg) } \\
\hline Baselinet & $59 \pm 6$ & $58 \pm 5$ & $59 \pm 5$ & $62 \pm 6$ & 0.19 \\
\hline$\geq 95$ th percentile, $\mathrm{n}(\%)$ & $12(15.8)$ & $2(6.1)$ & $8(13.8)$ & $5(29.4)$ & 0.47 \\
\hline Follow-up $\ddagger$ & $62 \pm 6$ & $63 \pm 7$ & $62 \pm 6$ & $64 \pm 7$ & 0.45 \\
\hline$\geq 70 \mathrm{~mm} \mathrm{Hg}, \mathrm{n}(\%)$ & $9(9.3)$ & $8(16.3)$ & $9(12.2)$ & $2(9.5)$ & 0.73 \\
\hline \multicolumn{6}{|l|}{ Any hypertension, n (\%) } \\
\hline Baselinet & $17(22.4)$ & $3(9.1)$ & $12(20.7)$ & $7(41.2)$ & 0.33 \\
\hline Follow-up $\ddagger$ & $11(11.3)$ & $11(22.4)$ & $14(18.9)$ & $6(28.6)$ & 0.053 \\
\hline \multicolumn{6}{|l|}{ SBP nocturnal dipping (\%) } \\
\hline Baselinet & $11.4 \pm 5.0$ & $12.8 \pm 4.9$ & $9.9 \pm 5.7$ & $7.6 \pm 7.4 \S$ & 0.009 \\
\hline Follow-up $\ddagger$ & $10.1 \pm 4.8$ & $9.6 \pm 6.0$ & $10.5 \pm 5.4$ & $6.3 \pm 5.7 \S$ & 0.15 \\
\hline \multicolumn{6}{|l|}{ SBP non-dipping, n (\%) } \\
\hline Baselinet & $29(38.2)$ & $9(27.3)$ & $25(43.1)$ & $11(64.7)$ & 0.097 \\
\hline Follow-up $\ddagger$ & $53(54.6)$ & $27(55.1)$ & $35(47.3)$ & $17(81.0)$ & 0.48 \\
\hline \multicolumn{6}{|l|}{ DBP nocturnal dipping (\%) } \\
\hline Baselinet & $17.3 \pm 6.7$ & $19.7 \pm 7.4$ & $17.8 \pm 5.8$ & $15.8 \pm 7.2$ & 0.78 \\
\hline Follow-up $\ddagger$ & $14.5 \pm 6.4$ & $14.2 \pm 7.5$ & $15.2 \pm 6.3$ & $11.9 \pm 8.0$ & 0.60 \\
\hline \multicolumn{6}{|l|}{ DBP non-dipping, n (\%) } \\
\hline Baselinet & $10(13.2)$ & $2(6.1 \%$ & $6(10.3)$ & $3(17.6)$ & 0.97 \\
\hline Follow-upł & $22(22.7)$ & $16(32.7)$ & $14(18.9)$ & $7(33.3)$ & 0.84 \\
\hline
\end{tabular}

* $\mathrm{P}$ values obtained from linear contrast tests and linear-by-linear association tests for continuous and categorical data, respectively.

†59 missing.

$\ddagger 2$ missing.

$\S \mathrm{P}<0.05$ after Bonferroni adjustment, compared with the normal group.

BP, Blood Pressure; DBP, Diastolic Blood Pressure; OSA, Obstructive Sleep Apnoea; SBP, Systolic Blood Pressure.

OSA at baseline was defined by an OAHI of $\geq 1$ event/hour. Mild childhood OSA was defined as an OAHI between 1 and 5 events/hour, while moderate-to-severe childhood OSA was defined as an OAHI of $\geq 5$ events/hour. OSA at follow-up was defined by an OAHI of $\geq 5$ events/hour as the subjects had already reached late adolescence or early adulthood. ${ }^{36}$ Mild adult OSA was defined by an OAHI between 5 and 15 events/ hour, while moderate-to-severe OSA was defined by an OAHI of $\geq 15$ events/hour. Primary snoring was defined when a subject had self-reported or parent-reported habitual snoring (at least three nights per week) in the past 12 months with an OAHI below the diagnostic cut-off for OSA. Same definitions were adopted in our recent publication on the natural history of childhood OSA. ${ }^{31}$

\section{ABP measurement}

All participants underwent 24-hour ABP monitoring, which was carried out on the day of overnight PSG with a validated oscillometric monitor (Spacelabs 90217, Spacelabs Healthcare). The 
proper-sized cuff was placed on the non-dominant arm. SBP, diastolic blood pressure (DBP) and mean arterial pressure (MAP) were measured every $30 \mathrm{~min}$ during the period from 21:30 to 07:30 (nocturnal sleep period) and every 15 min outside of this period (daytime wake period). The exact cut-off dividing wake and sleep BP were defined according to the PSG tracings. Individual mean SBP and DBP were calculated for wake and sleep periods. Recordings were accepted if there were at least 40 successful readings for the entire 24-hour period with a minimum of one successful reading per hour. ${ }^{37}$ Hypertension at baseline was defined when SBP or DBP at daytime, night-time or over a 24-hour period was $\geq 95$ th percentile with reference to height based on local norms. ${ }^{38}$ Hypertension at follow-up was defined as having SBP at daytime, night-time and 24 hours of $\geq 135$, 120 and $130 \mathrm{~mm} \mathrm{Hg}$, respectively; or DBP at daytime, nighttime and 24 hours of $\geq 85,70$ and $80 \mathrm{~mm} \mathrm{Hg}$, respectively. ${ }^{39}$ Degree of nocturnal dipping was calculated as the percentage drop of BP from wakefulness to sleep [(wake BP-sleep BP)/ wake $\mathrm{BP} \times 100 \%]{ }^{411}$ Non-dipping of nocturnal BP was defined as $<10 \%$ nocturnal drop of $\mathrm{BP}^{11}$

\section{Sample size}

Assuming a follow-up rate of $40 \%$ of total 619 children with $40 \%, 20 \%, 31 \%$ and $9 \%$, respectively, were normal controls, primary snorers, having mild and moderate-to-severe OSA at baseline, a sample size of 20-80 in each group with different OSA severity at baseline and 100 normal controls would be sufficient to detect an effect size of 0.4 (equivalent to $3.9 \mathrm{~mm} \mathrm{Hg}$ SBP and $2.5 \mathrm{~mm} \mathrm{Hg} \mathrm{DBP)} \mathrm{to} 0.7$ (equivalent to $6.8 \mathrm{~mm} \mathrm{Hg} \mathrm{SBP}$ and $4.3 \mathrm{~mm}$ Hg DBP) between OSA and control groups, with a statistical power of $80 \%$ and an alpha of $5 \%$.

\section{Statistical analysis}

$\chi^{2}$ tests, $\mathrm{t}$-tests and Mann-Whitney $\mathrm{U}$ tests with Bonferroni corrected $\mathrm{p}$ values were used to assess differences in baseline characteristics by inclusion in the 10 -year follow-up for categorical, normally distributed and non-normally distributed data, respectively. Linear contrast tests and linear-by-linear association tests with Bonferroni corrected $\mathrm{p}$ values for continuous and categorical data, respectively, to assess differences in baseline characteristics and BP at baseline and follow-up by baseline OSA severity and by childhood OSA status. We used Pearson correlation to assess the correlations of SBP and DBP (daytime, night-time and dipping) at follow-up with height, BMI and logtransformed OAHI at follow-up. Multivariate linear regression was used to assess the associations of baseline childhood OSA status with SBP, DBP and dipping of nocturnal BP at follow-up. Potential confounders, defined as factors potentially related to childhood OSA and BP outcomes in adulthood, were sex, age, BMI, height and parents' self-reported hypertension (either parent vs none) at baseline (figure 1). Robustness of the results was examined by additionally adjusting for other potential confounders for BP outcomes, including OAHI and ODI at follow-up in subsequent models. We tested whether the associations of childhood OSA (log-transformed OAHI) and BP in adulthood differed by sex, age/pubertal staging at baseline, BMI, OAHI and oxygen saturation at follow-up. To assess the adjusted associations of childhood OSA with risks of hypertension and non-dipping of nocturnal BP in adulthood, multivariable logbinomial regression was used with inverse probability weighting and relative risks (RRs) with 95\% CIs reported. To generate the inverse probability weights of response for each included participant in the regression analysis, logistic regression on baseline predictors was built to estimate the probability of being included in the follow-up. Statistical analyses were performed using $\mathrm{R}$ V.3.3.2 (R Development Core Team, Vienna, Austria) and SPSS statistical software package V.21.0 for Windows.

\section{RESULTS}

\section{Sample characteristics}

From the original 619 participants, 243 (59\% male) attended the 10-year follow-up visit, giving a response rate of $39 \%$. Detailed characteristics of the participants have been reported in our recent publication. ${ }^{31}$ The mean age of the respondents at follow-up was $20.2 \pm 1.9$ years, ranging from 16.1 to 25.0 years. Higher proportion of participants with childhood primary snoring and lower proportion of those with moderate-to-severe childhood OSA attended. However, baseline characteristics of the respondents were comparable to the non-respondents except that former with mild childhood OSA had a higher prevalence of allergic rhinitis $(\mathrm{p}=0.049)^{31}$ (online supplementary table 1 ). Forty per cent, $20 \%, 31 \%$ and $9 \%$ of the participants, respectively, were normal controls and primary snorers having mild and moderate-to-severe OSAs at baseline. At baseline, OSA was associated with higher BMI z-score and a higher prevalence of parent-reported habitual snoring (table 1). Participants with moderate-to-severe childhood OSA had higher nocturnal SBP at both baseline and follow-up, and they were more likely to have nocturnal systolic hypertension and reduced nocturnal dipping of SBP at follow-up (table 2).

At follow-up ABP was available in all but two participants with insufficient successful measurements and their results were excluded. One participant with outlying OAHI (80.9 events/ hour) at baseline was also excluded. Characteristics at baseline and follow-up by OSA categories at follow-up are shown in online supplementary table 2 . Respectively $64 \%, 12 \%, 16 \%$ and $8 \%$ were classified as normal, having primary snoring, mild OSA and moderate-to-severe OSA at follow-up. Majority of those who had moderate-to-severe OSA were male, they also had higher BMI z-score, higher daytime SBP and DBP, and higher nocturnal SBP at follow-up (online supplementary table 2). The positive correlations of $\mathrm{ABP}$ with height, $\mathrm{BMI}$ and $\log \mathrm{OAHI}$ at follow-up were more significant for SBP compared with DBP (figure 2). Nocturnal BP dipping in both SBP and DBP did not correlate with height, BMI and OAHI at follow-up (figure 2).

\section{Associations of baseline OSA with BP outcomes at follow-up}

Compared with participants who were disease free, those with moderate-to-severe OSA at baseline, but not mild OSA or primary snoring, had higher nocturnal SBP and reduced nocturnal SBP and MAP dipping at follow-up, after adjusting for sex, age, BMI, height and parental hypertension (table 3). Adjusted nocturnal SBP at follow-up was $6.5 \mathrm{~mm} \mathrm{Hg}(95 \% \mathrm{CI}$ 2.9 to 10.1) higher, and the adjusted degree of nocturnal SBP dipping was $4.1 \%$ (95\% CI $-6.3 \%$ to $1.8 \%$ ) lower in those with childhood moderate-to-severe OSA than those without OSA $(\mathrm{p}<0.05)$. The significant differences remained after additional adjustment for BMI, OAHI and ODI at follow-up. These associations did not vary by sex, age at baseline, BMI or OAHI/ODI at follow-up.

Moderate-to-severe OSA at baseline compared with participants who were disease-free was associated with higher risk of hypertension (RR 2.5, 95\% CI 1.2 to 5.3) and non-dipping in nocturnal SBP (RR 1.3, 95\% CI 1.0 to 1.7) and MAP (RR 1.8, 95\% CI 1.3 to 2.4) after adjusting for sex, age, BMI and height at baseline, height at follow-up and parental hypertension. This 


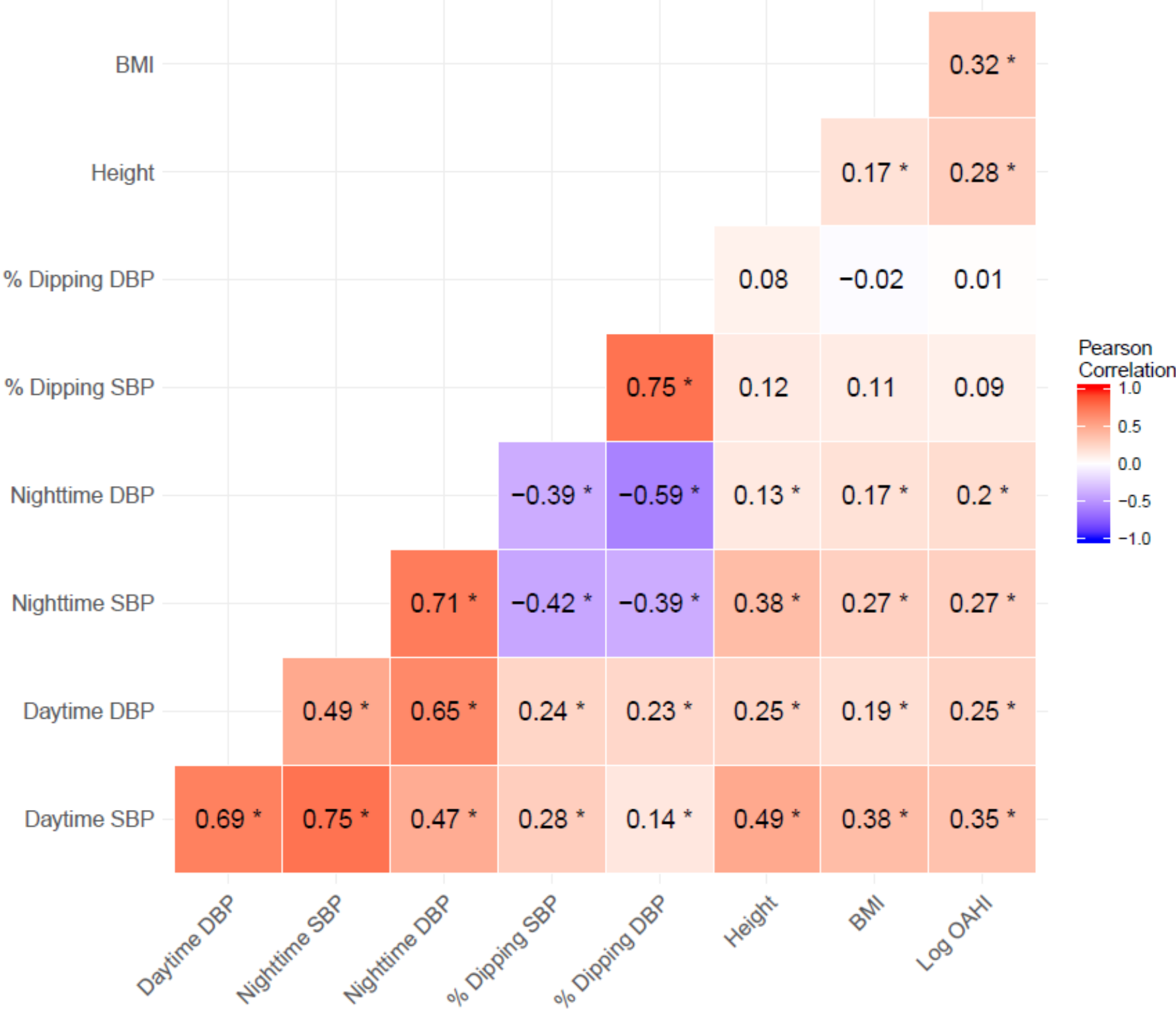

Figure 2 Heat map showing correlations of SBP and DBP (daytime, night-time and dipping) at follow-up with height, BMI and log-transformed $\mathrm{OAHI}$ at follow-up. ${ }^{*} \mathrm{P}<0.05$. BMI, body mass index; DBP, diastolic blood pressure; OAHI, obstructive apnoea-hypopnea index; SBP, systolic blood pressure.

association however, was not demonstrated in nocturnal diastolic hypertension or non-dipping of DBP (table 4). Moreover, moderate-to-severe OSA at baseline was significantly associated with higher nocturnal SBP and reduced SBP dipping regardless of OSA status at follow-up after adjusting for sex, age, BMI and height at baseline, height at follow-up and parental hypertension (table 5). There was a trend that individuals with both childhood moderate-to-severe OSA and adult OSA had higher SBP at follow-up than those who had only childhood disease (table 5).

\section{DISCUSSION}

This prospective 10-year follow-up study showed that moderateto-severe childhood OSA was independently and significantly associated with higher nocturnal SBP, hypertension and reduced nocturnal dipping of SBP in early adulthood. Our findings supported childhood OSA as an independent determinant of BP outcomes in adulthood and could be a potentially modifiable childhood factor contributing to future development of hypertension and other cardiovascular adverse outcomes. A threshold effect was also evident as only more severe OSA was associated with longer-term adverse BP outcomes.

While multiple cross-sectional studies have demonstrated the association between OSA and elevated BP, data from longitudinal follow-up studies are valuable in terms of evidence hierarchy in supporting this association. Our findings are consistent with our previous work that documented OSA severity to be independently associated with BP measurements at 4-year follow-up in non-obese children. ${ }^{4}$ The current study further identified that this association remained so regardless of the participants' OSA severity at follow-up. Although there was a trend where individuals with both childhood and adult OSAs had higher SBP at follow-up than those who had only childhood OSA, the associations between moderate-to-severe childhood OSA and worse adult BP outcomes were independent of their current OSA status. This may suggest OSA-related vascular remodelling can begin early in childhood and leads to persistent BP abnormalities. 
Table 3 Differences in ambulatory BP indices at 10-year follow-up (95\% CI) by OSA status at baseline using normal as reference

\begin{tabular}{|c|c|c|c|c|c|c|c|c|c|c|}
\hline \multirow[b]{2}{*}{ BP parameters } & \multirow[b]{2}{*}{ Model } & \multicolumn{4}{|c|}{ OSA status at baseline } & \multicolumn{5}{|c|}{ P for interaction $¥$} \\
\hline & & $\begin{array}{l}\text { Normal } n=98 \\
(40 \%)\end{array}$ & $\begin{array}{l}\text { Primary snoring } \\
n=49(20 \%)\end{array}$ & $\begin{array}{l}\text { Mild OSA } n=75 \\
(31 \%)\end{array}$ & $\begin{array}{l}\text { Moderate/severe OSA } \\
n=21(8.6 \%)\end{array}$ & Sex & $\begin{array}{l}\text { Age } \\
\text { (baseline) }\end{array}$ & $\begin{array}{l}\text { BMI } \\
\text { (follow-up) }\end{array}$ & $\begin{array}{l}\text { OAHI (follow- } \\
\text { up) }\end{array}$ & $\begin{array}{l}\text { ODI } \\
\text { (follow-up) }\end{array}$ \\
\hline \multirow{4}{*}{$\begin{array}{l}\mathrm{SBP}(\mathrm{mm} \mathrm{Hg}) \\
\text { (daytime) }\end{array}$} & 1 & Ref & $0.0(-3.0$ to 3.6$)$ & $0.0(-2.5$ to 2.5$)$ & $1.6(-1.9$ to 5.2$)$ & 0.91 & $0.02^{*}$ & 0.74 & 0.49 & 0.09 \\
\hline & 2 & Ref & $0.5(-2.4$ to 3.3$)$ & $0.4(-1.9$ to 2.8$)$ & $2.6(-0.7$ to 6.0$)$ & & & & & \\
\hline & 3 & Ref & -0.1 ( -3.1 to 2.8$)$ & -0.1 ( -2.5 to 2.4$)$ & $1.0(-2.5$ to 4.5$)$ & & & & & \\
\hline & 4 & Ref & -0.2 ( -3.3 to 2.9$)$ & 0.0 (-2.5 to 2.6$)$ & $1.6(-2.3$ to 5.6$)$ & & & & & \\
\hline \multirow{4}{*}{$\begin{array}{l}\mathrm{SBP}(\mathrm{mm} \mathrm{Hg}) \\
\text { (night-time) }\end{array}$} & 1 & Ref & $1.0(-2.1$ to 4.2$)$ & $-0.4(-3.0$ to 2.2$)$ & $6.5^{* * *}(2.9$ to 0.1$)$ & 0.58 & 0.11 & 0.44 & 0.54 & 0.58 \\
\hline & 2 & Ref & 1.3 (-1.8 to 4.3$)$ & $-0.2(-2.7$ to 2.3$)$ & $7.1^{* * *}$ (3.5 to 10.7$)$ & & & & & \\
\hline & 3 & Ref & $0.8(-2.3$ to 3.9$)$ & $-0.6(-3.1$ to 2.0$)$ & $6.0^{* *}(2.4$ to 9.7$)$ & & & & & \\
\hline & 4 & Ref & $0.6(-2.6$ to 3.9$)$ & $-0.5(-3.2$ to 2.2$)$ & $7.0^{* * *}(2.9,11.1)$ & & & & & \\
\hline \multirow[t]{4}{*}{ SBP (\% dipping) } & 1 & Ref & $-0.9(-2.9$ to 1.0$)$ & $0.4(-1.3$ to 2.0$)$ & $-4.1^{* * *}(-6.3$ to -1.8$)$ & 0.36 & 0.48 & 0.36 & 0.62 & 0.25 \\
\hline & 2 & Ref & $-0.8(-2.8$ to 1.1$)$ & $0.4(-1.2$ to 2.1$)$ & $-3.8^{* *}(-6.1$ to -1.5$)$ & & & & & \\
\hline & 3 & Ref & $-1.0(-2.9$ to 1.0$)$ & $0.3(-1.3$ to 2.0$)$ & $-4.8^{* * *}(-6.5$ to -1.9$)$ & & & & & \\
\hline & 4 & Ref & $-0.8(-3.0$ to 1.3$)$ & $0.3(-1.5$ to 2.1$)$ & $-4.5^{* *}(-7.2$ to -1.7$)$ & & & & & \\
\hline \multirow{4}{*}{$\begin{array}{l}\mathrm{DBP}(\mathrm{mm} \mathrm{Hg}) \\
\text { (daytime) }\end{array}$} & 1 & Ref & $0.9(-1.3$ to 3.2$)$ & $0.3(-1.5$ to 2.2$)$ & $-0.2(-2.8$ to 2.4$)$ & 0.73 & 0.06 & 0.34 & 0.46 & 0.30 \\
\hline & 2 & Ref & $1.1(-1.1$ to 3.3$)$ & $0.5(-1.3$ to 2.3$)$ & 0.2 (-2.4 to 2.8$)$ & & & & & \\
\hline & 3 & Ref & $0.8(-1.4$ to 3.0$)$ & $0.3(-1.5$ to 2.1$)$ & $-0.6(-3.1$ to 2.0$)$ & & & & & \\
\hline & 4 & Ref & $0.7(-1.6$ to 3.1$)$ & $0.5(-1.5$ to 2.4$)$ & $1.0(-2.0$ to 3.9$)$ & & & & & \\
\hline \multirow{4}{*}{$\begin{array}{l}\mathrm{DBP}(\mathrm{mm} \mathrm{Hg}) \\
\text { (night-time) }\end{array}$} & 1 & Ref & $1.2(-1.2$ to 3.5$)$ & $-0.2(-2.2$ to 1.7$)$ & $1.8(-1.0$ to 4.5$)$ & 0.76 & 0.06 & 0.56 & 0.42 & 0.73 \\
\hline & 2 & Ref & $1.3(-1.0$ to 3.7$)$ & $-0.1(-2.0$ to 1.9$)$ & $2.1(-0.6$ to 4.9$)$ & & & & & \\
\hline & 3 & Ref & $1.0(-1.3$ to 3.3$)$ & $-0.3(-2.3$ to 1.6$)$ & $1.3(-1.4$ to 4.1$)$ & & & & & \\
\hline & 4 & Ref & $1.0(-1.5$ to 3.4$)$ & -0.5 ( -2.5 to 1.6$)$ & $2.5(-0.6$ to 5.6$)$ & & & & & \\
\hline \multirow[t]{4}{*}{ DBP (\% dipping) } & 1 & Ref & $-0.5(-3.1$ to 2.0$)$ & 0.8 (-1.3 to 2.9$)$ & $-2.6+(-5.6$ to 0.3$)$ & 0.42 & 0.90 & 0.54 & 0.73 & 0.57 \\
\hline & 2 & Ref & $-0.6(-3.1$ to 1.9$)$ & 0.7 (-1.4 to 2.8$)$ & $-2.7+(-5.7$ to 0.3$)$ & & & & & \\
\hline & 3 & Ref & $-0.5(-3.1$ to 2.0$)$ & 0.8 (-1.3 to 2.9$)$ & $-2.6+(5.6$ to 0.4$)$ & & & & & \\
\hline & 4 & Ref & $-0.6(-3.2$ to 2.1$)$ & $1.2(-1.1$ to 3.4$)$ & $-2.2(-5.6$ to 1.12$)$ & & & & & \\
\hline \multirow{4}{*}{$\begin{array}{l}\text { MAP (mm Hg) } \\
\text { (daytime) }\end{array}$} & 1 & Ref & 0.5 (-1.6 to 2.6$)$ & $0.5(-1.2$ to 2.2$)$ & $0.7(-1.8$ to 3.1$)$ & 0.67 & $0.01^{*}$ & 0.28 & 0.75 & 0.11 \\
\hline & 2 & Ref & $0.7(-1.3$ to 2.8$)$ & 0.7 (-0.9 to 2.4$)$ & $1.2(-1.2$ to 3.6$)$ & & & & & \\
\hline & 3 & Ref & $0.4(-1.7$ to 2.4$)$ & $0.4(-1.3$ to 2.1$)$ & $0.2(-2.2$ to 2.7$)$ & & & & & \\
\hline & 4 & Ref & 0.3 (-1.9 to 2.4$)$ & 0.6 (-1.2 to 2.4$)$ & $1.3(-1.4$ to 4.1$)$ & & & & & \\
\hline \multirow{4}{*}{$\begin{array}{l}\text { MAP (mm Hg) } \\
\text { (night-time) }\end{array}$} & 1 & Ref & 0.5 (-1.7 to 2.8$)$ & $-0.2(-2.1$ to 1.7$)$ & $3.0^{*}(0.4$ to 5.6$)$ & 0.64 & 0.15 & 0.79 & 0.64 & 0.76 \\
\hline & 2 & Ref & $0.7(-1.5$ to 2.9$)$ & $-0.1(-1.9$ to 1.8$)$ & to $3.4^{*}(0.8$ to 6.0$)$ & & & & & \\
\hline & 3 & Ref & 0.4 (-1.9 to 2.6$)$ & $-0.3(-2.2$ to 1.5$)$ & $2.6+(-0.0,5.2)$ & & & & & \\
\hline & 4 & Ref & 0.4 (-2.0 to 2.7$)$ & $-0.4(-2.3$ to 1.6$)$ & $3.7^{*}(0.7$ to 6.6$)$ & & & & & \\
\hline \multirow[t]{4}{*}{ MAP (\% dipping) } & 1 & Ref & $-0.2(-2.2$ to .8$)$ & $0.8(-0.8$ to 2.5$)$ & $-2.7^{*}(-5.0$ to -0.3$)$ & 0.29 & 0.45 & 0.28 & 0.93 & 0.34 \\
\hline & 2 & Ref & $-0.2(-2.2$ to 1.8$)$ & $0.9(-0.8$ to 2.5$)$ & $-2.6^{*}(-5.0$ to -0.3$)$ & & & & & \\
\hline & 3 & Ref & -0.2 ( -2.3 to 1.8$)$ & $0.8(-0.9$ to 2.5$)$ & $-2.7^{*}(-5.1$ to -0.4$)$ & & & & & \\
\hline & 4 & Ref & $-0.2(-2.4$ to 1.9$)$ & $1.0(-0.8$ to 2.8$)$ & $-2.8^{*}(-5.5$ to -0.1$)$ & & & & & \\
\hline
\end{tabular}

Model 1 adjusted for sex, age, BMI at baseline and height at baseline, height at follow-up and parental self-reported hypertension (either parent vs none).

Model 2 adjusted for all variables in model 1 plus BMI at follow-up.

Model 3 adjusted for all variables in model 1 plus $\mathrm{OAHI}$ at follow-up.

Model 4 adjusted for all variables in model 1 plus ODI at follow-up.

${ }^{*} \mathrm{P}<0.05,{ }^{* *} \mathrm{P}<0.01,{ }^{* * *} \mathrm{P}<0.001$.

$+\mathrm{P}<0.10$.

łInteraction term of log-transformed OAHI with variable undertested.

BMI, Body Mass Index; BP, Blood Pressure; DBP, Diastolic Blood Pressure; MAP, Mean Arterial Pressure; OAHI, Obstructive Apnoea-Hypopnoea Index; ODI, Oxygen Desaturation Index; OSA, Obstructive Sleep Apnoea; Ref, Reference; SBP, Systolic Blood Pressure.

This underscores the importance of early recognition and treatment of childhood OSA. Nonetheless, studies that examined BP at follow-up as a primary outcome in children with SDB have reported conflicting results. ${ }^{27} 40-42$ Decline in overnight beatto-beat BP in children with improved SDB is found in a 4-year follow-up study. ${ }^{27}$ A significant reduction in DBP readings using office BP in children with resolved OSA was documented at follow-ups of 1 year and 2-14 months. ${ }^{41}$ However, no difference in BP measurements at baseline and follow-up is demonstrated using ABP monitoring. ${ }^{42}$ Different sampling frame, BP 
Table 4 Relative risks $(95 \% \mathrm{Cl})$ of any hypertension and BP non-dipping at 10 year follow-up by OSA status at baseline.

\begin{tabular}{llllll}
\hline & \multicolumn{5}{l}{ OSA status at baseline } \\
\cline { 2 - 6 } BP parameters & $\%$ & Normal & Primary snoring & Mild OSA & Moderate/severe 0SA \\
\hline Any hypertension & 17 & 1.0 & $1.9+(0.9$ to 4.2$)$ & $1.5(0.7$ to 3.0$)$ & $2.5^{*}(1.2$ to 5.3$)$ \\
Non-dipping & & & & & \\
SBP & 47 & 1.0 & $1.0(0.8$ to 1.4$)$ & $0.8(0.6$ to 1.1$)$ & $1.3^{*}(1.0$ to 1.7$)$ \\
DBP & 24 & 1.0 & $1.7 \dagger(1.0$ to 2.9$)$ & $0.8(0.4$ to 1.5$)$ & $1.7 \dagger(1.0$ to 2.9$)$ \\
MAP & 46 & 1.0 & $1.3(0.9$ to 1.9$)$ & $1.0(0.7$ to 1.5$)$ & $1.8^{* * *}(1.3$ to 2.4$)$ \\
\hline Ad
\end{tabular}

Adjusted for sex, age, Body Mass Index and height at baseline, height at follow-up and parental self-reported hypertension (either parent vs none).

${ }^{*} \mathrm{P}<0.05,{ }^{* *} \mathrm{P}<0.01,{ }^{* * *} \mathrm{P}<0.001$.

$+\mathrm{P}<0.10$.

BP, Blood Pressure; DBP, Diastolic Blood Pressure; MAP, Mean Arterial Pressure; OSA, Obstructive Sleep Apnoea; SBP, Systolic Blood Pressure.

monitoring tools and mix of patients with varying degrees of OSA severity could explain the aforementioned reported findings. A randomised controlled study to evaluate the effects of OSA intervention on BP parameters with repeated follow-up assessments is required to ascertain the possible causative role of childhood OSA on long-term BP.

Only moderate-to-severe childhood OSA was associated with worse BP outcomes, suggesting a threshold effect of OSA on BP control. This finding is consistent with previous reports on the cross-sectional association between OSA severity, cardiac function and structure and BP levels. Significantly higher BP, presence of nocturnal hypertension and ventricular dysfunction are seen only in more severe childhood OSA. ${ }^{363}$ In contrast, neurocognitive deficits, another important sequelae in children with OSA, are present even in those with primary snoring. ${ }^{44}$ Detailed delineation of the different PSG parameters, together with better OSA phenotyping, will explain the differential effects of OSA on clinical outcomes. Nocturnal rather than daytime BP measurements were associated with OSA in this study. This is explainable as mediating events, namely, abnormal gaseous exchange, arousals and sympathetic activation, take place during sleep. ${ }^{11}$ Other yet to be determined processes are likely to be involved as cross-sectional studies have shown higher nocturnal BP in childhood OSA even after exclusion of respiratory events. Elevated daytime BP is also documented in children with OSA. ${ }^{89}{ }^{45}$ The mechanism to explain this phenomenon is not completely understood and requires further examination. The differential effect on SBP but not DBP has previously been reported. ${ }^{43} 46$ The exact reason underlying this occurrence has not been fully elucidated; it is proposed that SBP is more vulnerable to intermittent hypoxia and sympathetic activation. ${ }^{43} 46$
Whether prolonged disease would lead to 'overspill' and cause daytime and DBP abnormalities should be examined. Nocturnal BP dipping is a physiological phenomenon, the absence of which precedes the development of cardiovascular adverse events. ${ }^{11}$ Our previous 4-year follow-up study did not show significant differences in nocturnal BP dipping among groups with varying baseline OSA severity. ${ }^{4}$ In contrast, this current study demonstrated an association between moderate-to-severe childhood OSA with reduced nocturnal SBP dipping in adulthood. This may suggest the effects of OSA on BP dipping profile do take time to develop.

The mechanism by which childhood OSA affects BP was not examined in our current study. We demonstrated that the adverse effects on BP were independent of the subjects' OSA status at follow-up. A likely mechanism was the tracking of higher BP from childhood to adulthood, particularly in those who had moderate-tosevere OSA at baseline. ${ }^{47} \mathrm{BP}$ abnormalities and reduced nocturnal BP dipping are well known risk factors for stroke, cardiovascular disease and end-stage renal disease. ${ }^{11}{ }^{19}$ Childhood OSA as shown in this study is a potentially modifiable parameter leading to these adverse outcomes. Tackling childhood OSA could theoretically reduce future cardiovascular disease burden in our society and can have far-reaching public health implications. Paediatricians should routinely ask about OSA symptoms in their practice, and patients suspected to have the condition should be promptly evaluated and managed accordingly.

Our study was the first prospective longitudinal study to examine a cohort of participants from childhood to adulthood to evaluate the effects of OSA on cardiovascular outcomes. There were a few limitations to address. Participation rate of subjects from our original cohort was low and there was a possibility of

Table 5 Differences in SBP indices at 10-year follow-up (95\% CI) by OSA status at baseline using normal as reference in participants with/without OSA at follow-up

\begin{tabular}{|c|c|c|c|c|c|}
\hline \multirow[b]{2}{*}{ Outcome measures } & \multirow[b]{2}{*}{ OSA status at follow-up } & \multicolumn{4}{|c|}{ OSA status at baseline } \\
\hline & & Normal & PS & Mild & Moderate/severe \\
\hline \multirow[t]{2}{*}{ Nocturnal SBP (mm Hg) } & No OSA & Ref & $1.8(-1.8$ to 5.3$)$ & $0.4(-2.6$ to 3.3$)$ & $6.2^{*}(0.4$ to 12.0$)$ \\
\hline & OSA & $4.1+(-0.4$ to 8.6$)$ & $2.0(-3.5$ to 7.5$)$ & $0.8(-3.5$ to 5.2$)$ & $8.1^{* * *}$ (3.6 to 12.5$)$ \\
\hline \multirow[t]{2}{*}{ SBP nocturnal dipping (\%) } & No OSA & Ref & $-2.2^{*}(-4.5$ to -0.0$)$ & $-0.5(-2.4$ to 1.3$)$ & $-5.5^{* *}(-9.1$ to -2.0$)$ \\
\hline & OSA & $-2.3+(-5.1$ to 0.5$)$ & $1.2(-2.2$ to 4.6$)$ & $1.4(-1.3$ to 4.1$)$ & $-3.9^{* *}(-6.7$ to -1.1$)$ \\
\hline
\end{tabular}

Adjusted for sex, age, Body Mass Index and height at baseline, height at follow-up and parental self-reported hypertension (either parent vs none).

${ }^{*} \mathrm{P}<0.05,{ }^{* *} \mathrm{P}<0.01,{ }^{* *} \mathrm{P}<0.001$

$+\mathrm{P}<0.10$.

OSA, Obstructive Sleep Apnoea; OSA, obstructive sleep apnoea; OSA, Obstructive Sleep Apnoea; OSA, Obstructive Sleep Apnoea; SBP, Systolic Blood Pressure; SBP, Systolic Blood Pressure; SBP, Systolic Blood PressureSBP, Systolic Blood Pressure;

OSA, Obstructive Sleep Apnoea; OSA, obstructive sleep apnoea; OSA, Obstructive Sleep Apnoea; OSA, Obstructive Sleep Apnoea; SBP, Systolic Blood Pressure; SBP, Systolic Blood Pressure; SBP, Systolic Blood PressureSBP, Systolic Blood Pressure. 
selection bias. Inverse probability weighting was used to minimise such potential biases. Baseline characteristics including age, sociodemographic parameters, pubertal status, weight and selfreported sleep problems were comparable between respondents and non-respondents. Although our study showed that moderateto-severe childhood OSA was associated with worse BP outcomes in early adulthood regardless of their current OSA status, participants received different treatments at variable time points. In our cohort, $20 \%$ of children with OSA underwent surgery, while $14 \%$ received medical therapy such as intranasal corticosteroids. Many declined treatment primarily because they were recruited from the community and in their parents' perspective were relatively asymptomatic. There was heterogeneity to the timing of OSA resolution, and whether resolution was secondary to treatment or part of its natural history is unknown. As a result, the effects of OSA treatment on BP outcomes could not be assessed. It also highlighted the importance of following up subjects with moderate-to-severe childhood OSA even after intervention. We used 24-hour ABP monitoring, which provided a more accurate reflection of BP trend, pattern and diurnal variation..$^{18}$ This monitoring tool might cause arousals during cuff inflation and potentially alter BP measurements. ${ }^{48}$ However, it was shown in a previous study that sleep disturbance is minimal. ${ }^{17}$ Finally, data regarding factors that could influence BP control, such as dietary habit and exercise, were not recorded.

\section{CONCLUSION}

Our follow-up study demonstrated an independent association between childhood OSA with adverse BP outcomes in early adulthood. Future studies should investigate whether OSA treatment would lessen one's risk of developing BP abnormalities, and if proven, targeting this modifiable childhood factor would be a way forward to reduce future cardiovascular disease burden.

Acknowledgements The authors thank all the participants and their parents for their contribution in this study.

Contributors KCC conceptualised and designed the study; coordinated, supervised and performed the data collection; carried out the data analysis and interpretation; drafted the initial manuscript; revised the manuscript; and approved the final manuscript as submitted. CTA conceptualised and designed the study; coordinated, supervised and performed data collection; carried out the data analysis and interpretation; reviewed and revised the manuscript; and approved the final manuscript as submitted. LLH contributed to the study design, carried out the data analysis and interpretation, reviewed and revised the manuscript, and approved the final manuscript as submitted. YKW contributed to the study design and data interpretation, reviewed and revised the manuscript, and approved the final manuscript as submitted. AML conceptualised and designed the study, coordinated and supervised the data collection, carried out data interpretation, reviewed and revised the manuscript, and approved the final manuscript as submitted. All authors approved the final manuscript as submitted and agreed to be accountable for all aspects of the work.

Funding This research project was supported by the Research Grants Council of the Hong Kong Special Administrative Region, China (CUHK 470913).

Disclaimer The funder had no role in study design, data collection and analysis, preparation of the manuscript or in the decision to submit the paper for publication.

\section{Competing interests None declared.}

\section{Patient consent for publication Not required.}

Ethics approval The study was approved by the Joint Chinese University of Hong Kong-New Territories East Cluster Research Ethics Committee (CRE-2013-011).

Provenance and peer review Not commissioned; externally peer reviewed.

Data availability statement No data are available. Individual participant data will not be available.

\section{REFERENCES}

1 Li AM, So HK, Au CT, et al. Epidemiology of obstructive sleep apnoea syndrome in Chinese children: a two-phase community study. Thorax 2010;65:991-7.
2 Senaratna CV, Perret JL, Lodge CJ, et al. Prevalence of obstructive sleep apnea in the general population: a systematic review. Sleep Med Rev 2017;34:70-81.

3 Chan JYS, Li AM, Au C-T, et al. Cardiac remodelling and dysfunction in children with obstructive sleep apnoea: a community based study. Thorax 2009;64:233-9.

4 Li AM, Au CT, Ng C, et al. A 4-year prospective follow-up study of childhood OSA and its association with bp. Chest 2014;145:1255-63.

5 Dehlink E, Tan H-L. Update on paediatric obstructive sleep apnoea.J Thorac Dis 2016;8:224-35.

6 Li AM, Au CT, Sung RYT, et al. Ambulatory blood pressure in children with obstructive sleep apnoea: a community based study. Thorax 2008;63:803-9.

7 Chan KCC, Au CT, Chook P, et al. Endothelial function in children with OSA and the effects of adenotonsillectomy. Chest 2015;147:132-9.

8 Nisbet LC, Yiallourou SR, Biggs SN, et al. Preschool children with obstructive sleep apnea: the beginnings of elevated blood pressure? Sleep 2013;36:1219-26.

9 Horne RSC, Yang JSC, Walter LM, et al. Elevated blood pressure during sleep and wake in children with sleep-disordered breathing. Pediatrics 2011;128:e85-92.

10 Wolk R, Shamsuzzaman ASM, Somers VK. Obesity, sleep apnea, and hypertension. Hypertension 2003;42:1067-74.

11 Crinion SJ, Ryan S, McNicholas WT. Obstructive sleep apnoea as a cause of nocturnal nondipping blood pressure: recent evidence regarding clinical importance and underlying mechanisms. Eur Respir J 2017;49:1601818.

12 Mokhlesi B, Hagen EW, Finn LA, et al. Obstructive sleep apnoea during REM sleep and incident non-dipping of nocturnal blood pressure: a longitudinal analysis of the Wisconsin sleep cohort. Thorax 2015;70:1062-9.

13 Seif F, Patel SR, Walia HK, et al. Obstructive sleep apnea and diurnal nondipping hemodynamic indices in patients at increased cardiovascular risk. J Hypertens 2014;32:267-75

$14 \mathrm{Li}$ AM, Au CT, Ho C, et al. Blood pressure is elevated in children with primary snoring. $J$ Pediatr 2009;155:362-8.

$15 \mathrm{Xu}$ Z, Li B, Shen K. Ambulatory blood pressure monitoring in Chinese children with obstructive sleep apnea/hypopnea syndrome. Pediatr Pulmonol 2013;48:274-9.

16 Weber SAT, Santos VIBdos, Semenzati GdeO, et al. Ambulatory blood pressure monitoring in children with obstructive sleep apnea and primary snoring. Int J Pediatr Otorhinolaryngol 2012;76:787-90.

17 Amin RS, Carroll JL, Jeffries JL, et al. Twenty-Four-Hour ambulatory blood pressure in children with sleep-disordered breathing. Am J Respir Crit Care Med 2004;169:950-6.

18 Pickering TG, Shimbo D, Haas D. Ambulatory blood-pressure monitoring. N Engl J Med 2006:354:2368-74.

19 Aatola H, Koivistoinen T, Tuominen H, et al. Influence of child and adult elevated blood pressure on adult arterial stiffness: the cardiovascular risk in young Finns study. Hypertension 2017;70:531-6.

20 Peppard PE, Young T, Palta M, et al. Prospective study of the association between sleep-disordered breathing and hypertension. N Engl J Med 2000;342:1378-84.

21 Mokhlesi B, Finn LA, Hagen EW, et al. Obstructive sleep apnea during REM sleep and hypertension. Results of the Wisconsin sleep cohort. Am J Respir Crit Care Med 2014; 190:1158-67.

22 Marin JM, Agusti A, Villar I, et al. Association between treated and untreated obstructive sleep apnea and risk of hypertension. JAMA 2012;307:2169-76.

23 Cano-Pumarega I, Durán-Cantolla J, Aizpuru F, et al. Obstructive sleep apnea and systemic hypertension: longitudinal study in the general population: the Vitoria sleep cohort. Am J Respir Crit Care Med 2011;184:1299-304.

24 O'Connor GT, Caffo B, Newman AB, et al. Prospective study of sleep-disordered breathing and hypertension: the sleep heart health study. Am J Respir Crit Care Med 2009;179:1159-64.

25 Bixler EO, Fernandez-Mendoza J, Liao D, et al. Natural history of sleep disordered breathing in prepubertal children transitioning to adolescence. Eur Respir J 2016;47:1402-9.

26 Bixler EO, Liao D, Vgontzas AN, et al. Incident sleep-disordered breathing is associated with higher blood pressure and its reactivity: Penn state child cohort. Circulation 2013;127:AMP84.

27 Vlahandonis A, Nixon GM, Davey MJ, et al. Improvement of sleep-disordered breathing in children is associated with a reduction in overnight blood pressure. Sleep Med 2013;14:1295-303.

28 Archbold KH, Vasquez MM, Goodwin JL, et al. Effects of sleep patterns and obesity on increases in blood pressure in a 5-year period: report from the Tucson children's assessment of sleep apnea study. J Pediatr 2012;161:26-30.

29 Horne RSC, Yang JSC, Walter LM, et al. Nocturnal dipping is preserved in children with sleep disordered breathing regardless of its severity. Pediatr Pulmonol 2013;48:1127-34.

30 Marcus CL, Greene MG, Carroll JL. Blood pressure in children with obstructive sleep apnea. Am J Respir Crit Care Med 1998;157:1098-103.

31 Chan KC, Au CT, Hui LL, et al. How OSA evolves from childhood to young adulthood: natural history from a 10-year follow-up study. Chest 2019;156:120-30

32 Li AM, Cheung A, Chan D, et al. Validation of a questionnaire instrument for prediction of obstructive sleep apnea in Hong Kong Chinese children. Pediatr Pulmonol 2006;41:1153-60. 
33 Leung SS, Cole TJ, Tse LY, et al. Body mass index reference curves for Chinese children. Ann Hum Biol 1998;25:169-74.

34 Chan NPT, Sung RYT, Kong AP, et al. Reliability of pubertal self-assessment in Hong Kong Chinese children. J Paediatr Child Health 2008;44:353-8.

35 Berry RB, Brooks R, Gamaldo CE, et al. Marcus Cl and Vaughn bv for the American Academy of sleep medicine. The AASM manual for the scoring of sleep and associated events: rules, terminology and technical specifications, version 2.0. Darien, Illinois: American Academy of Sleep Medicine, 2012. www.aasmnet.org

36 American Academy of Sleep Medicine. International classification of sleep disorders. 3rd ed. Darien, IL: American Academy of Sleep Medicine, 2014.

37 O'Brien E, Asmar R, Beilin L, et al. European Society of hypertension recommendations for conventional, ambulatory and home blood pressure measurement. J Hypertens 2003;21:821-48.

38 Yip GWK, Li AM, So H-K, et al. Oscillometric 24-h ambulatory blood pressure reference values in Hong Kong Chinese children and adolescents. J Hypertens 2014;32:606-19.

39 Leung AA, Daskalopoulou SS, Dasgupta K, et al. Hypertension Canada's 2017 guidelines for diagnosis, risk assessment, prevention, and treatment of hypertension in adults. Can J Cardiol 2017:33:557-76.

40 Apostolidou MT, Alexopoulos El, Damani E, et al. Absence of blood pressure, metabolic, and inflammatory marker changes after adenotonsillectomy for sleep apnea in Greek children. Pediatr Pulmonol 2008;43:550-60.
41 Amin R, Anthony L, Somers V, et al. Growth velocity predicts recurrence of sleepdisordered breathing 1 year after adenotonsillectomy. Am I Respir Crit Care Med 2008;177:654-9.

$42 \mathrm{Ng} \mathrm{DK}$, Wong JC, Chan C-H, et al. Ambulatory blood pressure before and after adenotonsillectomy in children with obstructive sleep apnea. Sleep Med 2010;11:721-5.

43 Bixler EO, Vgontzas AN, Lin H-M, et al. Blood pressure associated with sleep-disordered breathing in a population sample of children. Hypertension 2008;52:841-6.

44 Bourke R, Anderson V, Yang JSC, et al. Cognitive and academic functions are impaired in children with all severities of sleep-disordered breathing. Sleep Med 2011;12:489-96.

45 Kang K-T, Chiu S-N, Weng W-C, et al. Analysis of 24-hour ambulatory blood pressure monitoring in children with obstructive sleep apnea: a hospital-based study. Medicine 2015;94:e1568.

46 DelRosso LM, King J, Ferri R. Systolic blood pressure elevation in children with obstructive sleep apnea is improved with positive airway pressure use. J Pediatr 2018; 195:102-7.

47 Chen $X$, Wang Y. Tracking of blood pressure from childhood to adulthood: a systematic review and meta-regression analysis. Circulation 2008;117:3171-80.

48 Davies RJ, Jenkins NE, Stradling JR. Effect of measuring ambulatory blood pressure on sleep and on blood pressure during sleep. BMJ 1994;308:820-3. 